\title{
Advanced User Interface of Wheelchair based on Android
}

\section{D.Vijendra Babu, M.Karthick, C.Iyyapan}

\begin{abstract}
The Disabled peoples and Patients with physical injuries needs special attention and they should be able to navigate to the desired place through easy operable Wheelchair. The paper describes the setup in wheelchair for Automation which can be controlled by Smartphone operates on Android application. It uses a Microcontroller which drives the DC motor to various directions which resulting in Wheelchair movement. Android application controls the Wheelchair motions based on the commands from the User.
\end{abstract}

Index Terms: disabled patients, wheelchair, smartphone, android, microcontroller

\section{INTRODUCTION}

$\mathrm{R}$ Recent survey indicates the volume of differentially abled persons in India has increased in Rural and Urban locations in a Decade. Persons affected by paralysis are restricted to use Wheelchair and rely on other Humans for their movement and routine needs. So, customization of Wheelchair remains to be significant in enhancing the necessary accessories to the Wheelchair. Wide range of Wheelchair exists differing by Technology used, propulsion method and mechanisms of control. Wheelchairs are designed for continuous utilization to address the specific access needs. Various types of Wheelchair are available in market such as Voice controlled Wheelchair, Gesture controlled Wheelchair, Joystick controlled Wheelchair, Headcontrol Wheelchair, Smart Wheelchair and so on. Powered Wheelchair is an electric powered and controlled by User/attendant by the control placed on armrest. The principle behind designing a Wheelchair should result in free movement as they wish either in Indoor/Outdoor as they need with low complexity in operation.

\section{LITERATURE SURVEY}

Manuel Mazo, et all, describes a wheelchair model based on Ultrasonic sensor systems integrated with Wheelchair for differentially abled persons. The Wheelchair been controlled by audio instructions to avoid disturbances. H.R.Singh, et al, discusses about a motorized wheelchair controlled by voice or joystick. The Speed and Direction of

Revised Manuscript Received on September 22, 2019

Dr.D.Vijendra Babu,ECE Department, Aarupadai Veedu Institute of Technology, Vinayaka Mission's Research Foundation,Chennai,India. Email:vijendrababu@avit.ac.in

M.Karthick, ECE Department, Aarupadai Veedu Institute of Technology, Vinayaka Mission's Research Foundation, Chennai, India.

C.Iyyapan, ECE Department, Aarupadai Veedu Institute of Technology, Vinayaka Mission's Research Foundation,Chennai,India. the chair which can be controlled by pre-decided suitable voice commands or manually, using a Joystick switch are related to the linear movement of the joystick in forward or reverse directions.

Shawn Plesnick, et al, explains a method for implementing an Eye tracking device for controlling electrical wheelchair. Through the use of measured gaze points, it is possible to translate a desired movement into a physical one. This form of interface does not only provide a form of transportation for those with severe disability but also allow the user to get a sense of control back into their lives.

Kyung Mog Lee describes Electronic Wheelchair Controller with a Smart Phone's Speaker-independent Recognition Engine. The Smartphone was programed with a Google's speaker independent recognition engine and a Google map, which can be used as a remote controller for seven Voice commands: Left, Right, Forward, Backward, Faster, Slower and Stop. The recognition time for each one of the seven commands were measured.

R.K.Megalingam, et al, describes the concept of using an Android application in smart gadget in designing a Bluetooth-based Wheelchair controlled by finger or hand gesture. The device helps those deprived of movement in routine works. In certain situations, the differently abled might not be able to control their fingers. In such cases, Bluetooth is used where a second person can control the movement instead of pushing it.

\section{SYSTEM DESIGN}

The system comprises of Transmitter part and Receiver part. In, Transmitter part the Input is provided by the Android based software application. Obtained Digital Output is sent to the Microcontroller by means of Bluetooth interfacing with the module. This module will be placed on the Wheelchair and then the command is transmitted to receiver side by the RF Transmitter as displayed in Fig. 1. Android application controls the wheelchair movements Graphical User Interface (GUI) is provided via the application to the user to control the Wheelchair movements. A touch-screen based Android mobile is used to control the Wheelchair. Smartphone operated in Android is linked to Microcontroller placed inside Wheelchair via Bluetooth controller. 


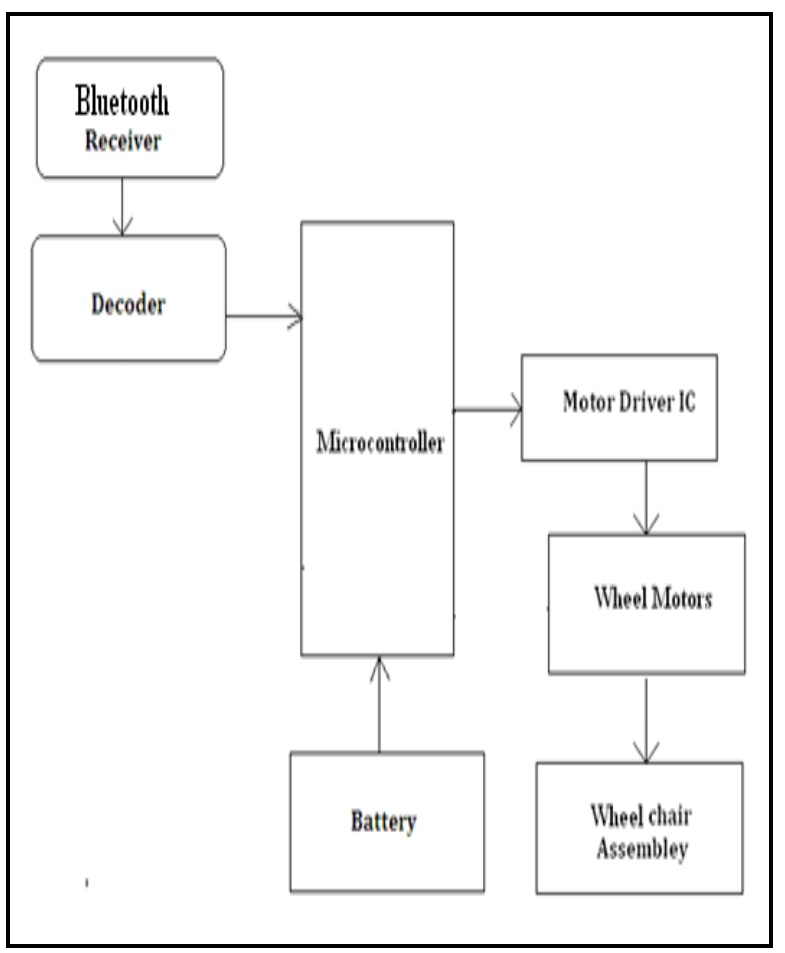

Fig. 1.Block Diagram

\section{HARDWARE MODULE}

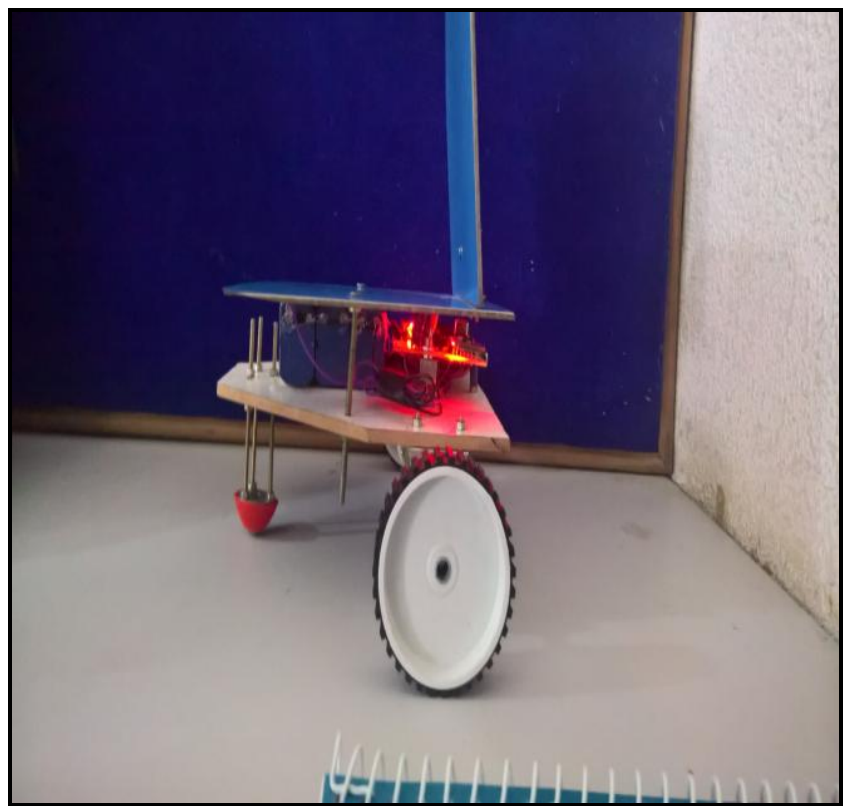

Fig. 2.Side View

A simple User interface is utilized by the User for selection of direction for motion of Wheelchair. Based on selected input option, the particular signal is sent through Bluetooth controller to Microcontroller (AT89S52). If User selects the Front direction, then both the Motors moves in the same direction and with same speed. If the User wants to move in the Left / Right direction than polarity of both the Motors are reversed correspondingly. The programming language used for developing the software to the Microcontroller is Embedded C.The KEIL Micro Vision cross compiler is used to edit, compile and debug this program.Wlpro programmer software downloads the program to Microcontroller. Control section has Battery to give the power to microcontroller and whole circuit. Fig. 2 \& Fig. 3 shows the side view and front view of the working module.

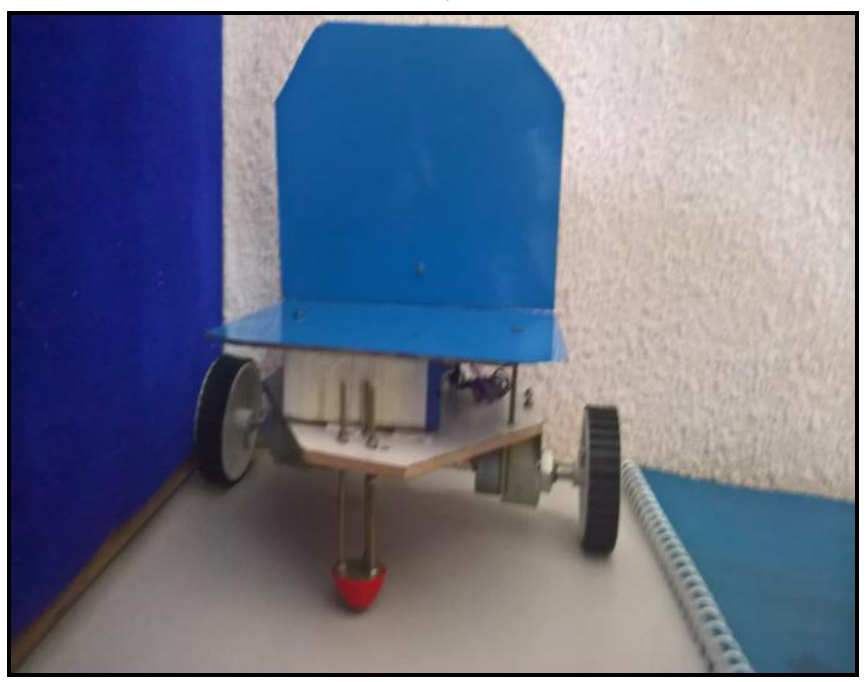

Fig. 3.Front View

\section{RESULT AND DISCUSSION}

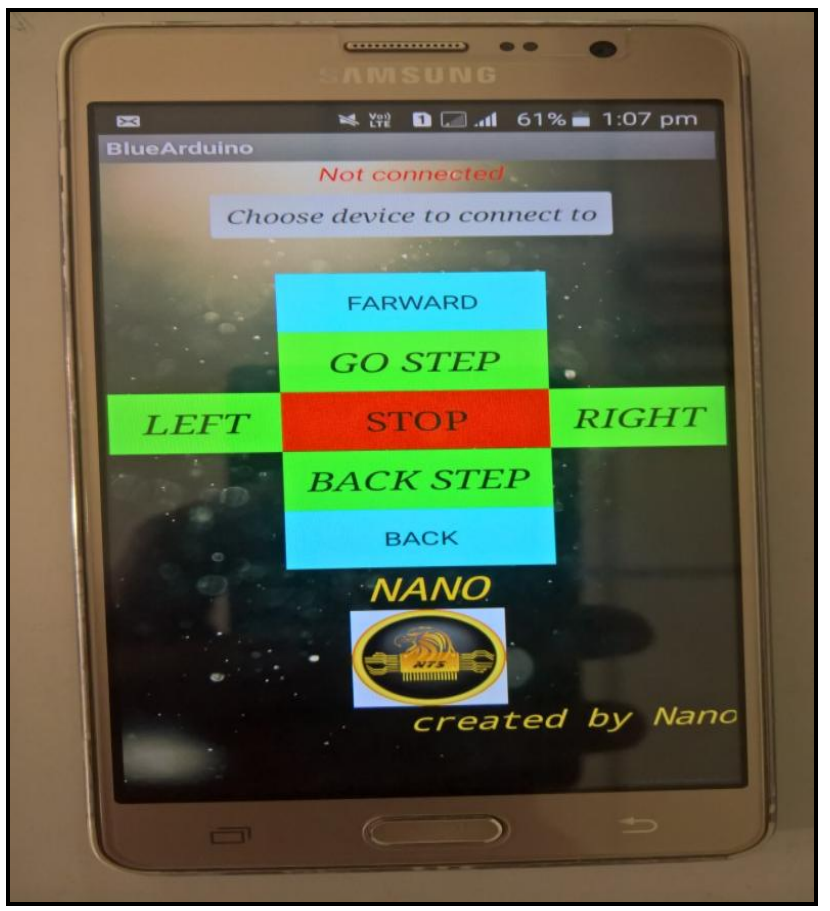

Fig. 4.Display in Android Mobile

Fig. 4 exhibits the display in the Android Mobile for display of the Wheelchair movement. It is been operated by the User for the desired Wheelchair motion.

\section{CONCLUSION}

Using the advanced user interface, differently abled people can move to desired location without requiring assistance from other person and without requiring physical stress. Android application controlled wheelchair motions can be controlled by the user by giving specific commands as displayed in

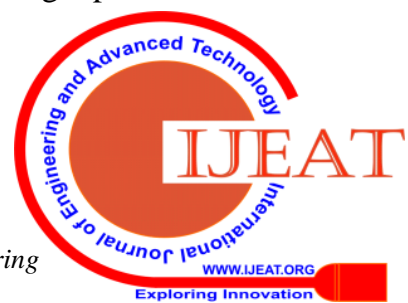


Fig.4 issued by a particular user. The User interface of Android application is simple and easy to use.

\section{REFERENCES}

1. Manuel Mazo, et al, "Wheelchair for physically disabled people with Voice, Ultrasonic and Infrared sensor control, Autonomous Robots", Springer, 1995, Volume 2, Number 3, pp.203.

2. H. R. Singh, et al, "Design and development of voice/joystick operated microcontroller based intelligent motorised Wheelchair", Proceedings of IEEE Region 10 Conference-TENCON 99, Multimedia Technology for Asia-Pacific Information Infrastructure, South Korea, 1999, Vol. 2, pp. 1573-1576.

3. Shawn Plesnick, et al, "Eye-Controlled Wheelchair", 2014 IEEE Canada International Humanitarian Technology Conference (IHTC), 978-1-4799-3996-1/14

4. Kyung Mog Lee, "Study on the Electronic Wheelchair Controller with a Smart Phone's Speaker-independent Recognition Engine", Proceedings of the World Congress on Engineering and Computer Science(WCECS), Vol. II, October 2015,USA.

5. R.K.Megalingam, et.al,"Wireless gesture controlled wheelchair", 2017 4th International Conference on Advanced Computing and Communication Systems (ICACCS), 2017,pp-1-5.

6. D.Vijendra Babu,et al, "MEMS based smart \& secure home automation system with multi-way control \& monitoring facility using smart phone", Journal of Chemical and Pharmaceutical Sciences, 2015-April, pp. 357-359.

7. D.Vijendra Babu, et al, "Automated Robotic receptionist with embedded touch screen", Journal of Chemical and Pharmaceutical Sciences, 2015-April, pp. 415-417.

\section{Authors ProfiLe}

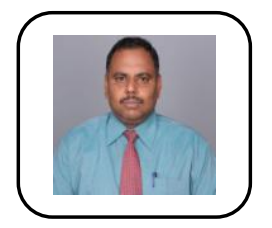

Dr.D.Vijendra Babu earned his Ph.D. from Jawaharlal Nehru Technological University, Hyderabad, M.Tech. from SASTRA Deemed to be University \& B.E. from University of Madras. He is currently designated as Vice Principal \& Professor.

He has 2 Decades of Experience in the field of Education, Research \& Administration at various levels. He has served as HoD for 13 Years \& delivered numerous Invited Lectures in the area of $5 \mathrm{G}$ Communication, Artificial Intelligence, Robotics \& Image/Video Processing at various Institutions. He has chaired several Sessions on International/National Conferences. He has published $80+$ papers in International Journals/Conferences. He is a recipient of Best Paper Award in IEEE International Conference \& Active ISF Award. He is Secretary of IEEE Robotics \& Automation Society. He is Senior Member of IEEE, Fellow of IETE, Life member in ISTE, BES (I), ACEEE \& IACSIT. 